\title{
Optical Microscopy-Based Damage Quantification: an Example of Cryogenic Deformation of a Dual-Phase Steel
}

\author{
Nao UEHATA, ${ }^{1)}$ Motomichi KOYAMA, ${ }^{1{ }^{* *}}$ Shusaku TAKAGI ${ }^{2)}$ and Kaneaki TSUZAKI ${ }^{11}$ \\ 1) Department of Mechanical Engineering, Kyushu University, Motooka 744, Nishi-ku, Fukuoka, Fukuoka, $819-0395$ Japan. \\ 2) Steel Research Laboratory, JFE Steel Corporation, 2-3, Uchisaiwai-cho 2-chome, Chiyoda-ku, Tokyo, $100-0011$ Japan.
}

(Received on August 9, 2017; accepted on September 14, 2017)

\begin{abstract}
We evaluated the availability of an optical-microscopy-based damage quantification method in a ferrite/ martensite dual-phase steel, and interpreted the obtained results toward screening damage evolution behavior under various test conditions. In this study, we employed this method for tensile deformation at $20,-100$, and $-180^{\circ} \mathrm{C}$ to analyze the temperature dependence of damage evolution in cryogenic regime as a case study. The damage evolution behavior was classified into regimes of damage nucleation, damage arrest, and damage growth to fracture, irrespective of the deformation temperature in a cryogenic temperature range. Coupled with some high-resolution observations, the damage nucleation and damage arrest sites were identified to be martensite and ferrite, which are common regardless of the deformation temperatures. This indicates that ferrite acted as a damage arrest site even at $-180^{\circ} \mathrm{C}$. However, a critical strain for damage growth to fracture decreased drastically by decreasing the temperature to $-180^{\circ} \mathrm{C}$. The distinct reduction in the critical strain is attributed to the transition of ferrite cracking mode from ductile to brittle mechanisms.
\end{abstract}

KEY WORDS: dual-phase steel; damage quantification; martensite cracking; damage arrest; ferrite; low temperature.

\section{Introduction}

Ferrite/martensite dual-phase (DP) steel has been used in automotive components owing to its high tensile strength coupled with good formability. ${ }^{1,2)}$ The superior mechanical properties are attributed to its high work-hardening capability associated with the large difference in strength between ferrite and martensite. ${ }^{3)}$ However, the high mechanical contrast causes microstructurally-local plastic strain ${ }^{4)}$ and the formation of micro-damage such as voids and cracks, ${ }^{5)}$ which degrade the local deformability ${ }^{6}$ and change the apparent Young's modulus. ${ }^{7)}$ Therefore, quantification of damage parameters is required for the design of advanced multi-phase high strength steels and the evaluation of effects of damage evolution on ductility.

From the viewpoint of damage quantification, various methods have been attempted, e.g., physical density measurement, ${ }^{8)}$ elastic constant measurement, ${ }^{9,10)}$ tomographic damage volume fraction measurement, ${ }^{11)}$ and microscopybased damage area fraction measurement. ${ }^{8,12)}$ According to Tasan's work, ${ }^{8)}$ in terms of the balance of precision, spatial resolution, and practicality, microscopy-based area fraction measurement is the most efficient methodology for damage quantification. Furthermore, average damage size, which is obtained from the area fraction measurement, has been reported to enable the classification of damage evolu-

* Corresponding author: E-mail: koyama@mech.kyushu-u.ac.jp DOI: http://dx.doi.org/10.2355/isijinternational.ISIJINT-2017-468 tion regimes in DP steels. ${ }^{12)}$ Plastic strain evolves without damage initiation in the first regime. In the second regime, damage forms frequently, but the damage is arrested until a critical strain for its growth. Then, the damage starts to grow until failure in the third regime. Specifically, the straincontrolled damage arrest regime (the second regime) on a micro-scale is important to characterize total elongation. Therefore, the strain dependence of average damage size must be characterized to sophisticatedly predict and design the elongation of DP steels.

Currently, damage quantification has been well developed to provide sufficient accuracy of damage parameters using scanning electron microscopy (SEM) ${ }^{8,12-14)}$ However, most of these works were carried out under limited experimental conditions such as a quasi-static tensile strain rate at room temperature. For further industrial application of the method, damage quantification must be performed at various conditions such as high deformation speed, cryogenic temperature etc. For instance, while automotive parts have a role in protecting passengers from impact in automobile collisions, it is important to evaluate the crashworthiness of the materials during high-speed deformation (e.g., $10^{2} \mathrm{~s}^{-1}$ or higher). ${ }^{15)}$ Moreover, since automotive parts are exposed to various temperatures depending on the season and location, the temperature dependence of damage formation behavior is also important. In particular, cryogenic deformation may exhibit unpredictable behavior owing to the occurrence of low-temperature embrittlement. Hence, quantitative screening of damage evolution behavior is required for further 
engineering applications. Accordingly, the damage quantification method must be facilitated for a wide range of screening.

In this study, we aim to demonstrate the availability of optical microscopy for damage quantification, instead of SEM. Among various test conditions, we focus on cryogenic damage evolution behavior and investigate the effects of test temperature in a DP steel as a first step toward systematic understanding of cryogenic failure. Notably, the temperature effect is correlated with the strain rate effect in terms of a thermally activated process of dislocation motion (see Appendix). Sub-micro size damage may not be detected by optical microscopy, but damage growth and damage arrest characteristics are expected to be quantified. Therefore, the optical-microscopy-based approach must be effective for the characterization of damage evolution after damage nucleation. Furthermore, we attempt to correlate the characterized damage evolution behavior with specific high-resolution microscopic characters using electron backscatter diffraction (EBSD) analysis and electron channeling contrast imaging (ECCI). Subsequently, we discuss the availability of opticalmicroscopy-based damage quantification and how the highresolution microstructure observations can compensate for the information lacking in the optical analysis.

\section{Experimental Procedure}

\subsection{Material}

A steel bar with a chemical composition shown in Table 1 was solution-treated at $1250^{\circ} \mathrm{C}$ for $30 \mathrm{~min}$. The bar was hot-rolled and subsequently cold-rolled to $1 \mathrm{~mm}$. In order to obtain a ferrite/martensite DP microstructure, the sheet was intercritically annealed at $800^{\circ} \mathrm{C}$ for $3 \mathrm{~min}$ and subsequently water quenched. The optical image of an undeformed microstructure on a transverse direction (TD) plane is shown in Fig. 1. The specimen of this image was etched with 3\% nital solution, followed by color etching with $5 \% \mathrm{Na}_{2} \mathrm{~S}_{2} \mathrm{O}_{5}$ aqueous solution on a mechanically polished specimen. After the color etching, ferrite and martensite appear as white and brown, respectively. According to the optical microscopic

Table 1. Chemical composition of the steel used (mass\%).

\begin{tabular}{cccccccc}
\hline $\mathrm{C}$ & $\mathrm{Si}$ & $\mathrm{Mn}$ & $\mathrm{P}$ & $\mathrm{S}$ & $\mathrm{Al}$ & $\mathrm{N}$ & $\mathrm{Fe}$ \\
\hline 0.073 & 0.492 & 1.52 & 0.009 & 0.0025 & 0.035 & 0.0007 & $\mathrm{Bal}$.
\end{tabular}

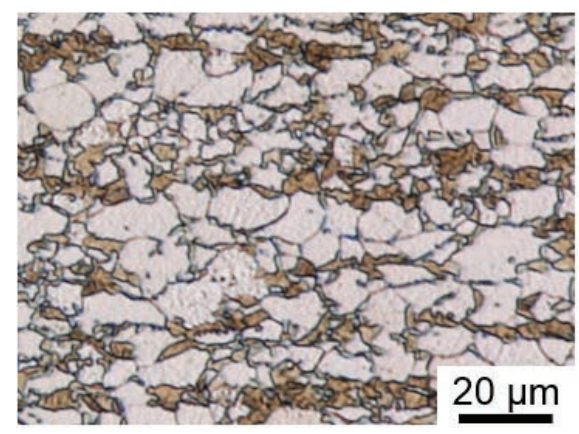

Fig. 1. Optical micrograph of the DP steel before tensile tests. It was obtained on the TD plane. The horizontal direction corresponds to the cold rolling direction and the tensile direction. (Online version in color.) observation on the color-etched surface, the fraction of martensite was measured to be $27 \%$.

\subsection{Tensile Test}

Tensile specimens with a gauge section of $2.0 \mathrm{~mm}$ (width) $\times 1.0 \mathrm{~mm}$ (thickness) $\times 8.0 \mathrm{~mm}$ (length) are shown in Fig. 2. The tensile tests were carried out along the rolling direction (RD) at an initial strain rate of $1.0 \times 10^{-2} \mathrm{~s}^{-1}$. The test temperatures were controlled at $20,-100$, and $-180^{\circ} \mathrm{C}$ in a thermostatic chamber. Since yield strength of a DP steel with a strain rate of $10^{2} \mathrm{~s}^{-1}$ at $20^{\circ} \mathrm{C}$ that corresponds to crashworthiness tests shows a similar value to that with a strain rate of $10^{-2} \mathrm{~s}^{-1}$ at a temperature between -50 and $-120^{\circ} \mathrm{C},{ }^{16)}$ one of the test temperatures was selected to be $-100^{\circ} \mathrm{C}$. The temperature of $-180^{\circ} \mathrm{C}$ is the lowest in the possible test condition of our tensile machine. During the tensile tests at $20^{\circ} \mathrm{C}$, optical images were captured to measure the local strain on the specimens via the digital image correlation (DIC) method, as shown in Fig. 3(a). A random pattern to apply the DIC method was formed by using a black spray on a specimen undercoated by white enamel. The local strain data were used to correlate the quantified damage parameters with strain as described in the following sections.

\subsection{Optical-microscopy-based Damage Quantification}

Damage quantification experiments were performed for the TD cross-sections along the tensile axis of the frac-

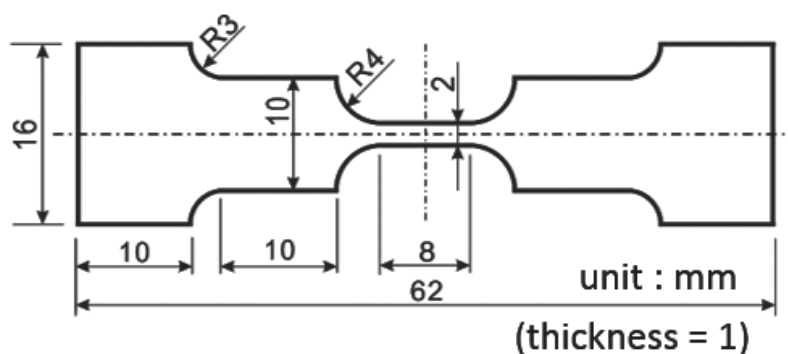

Fig. 2. Sample geometry for tensile testing.

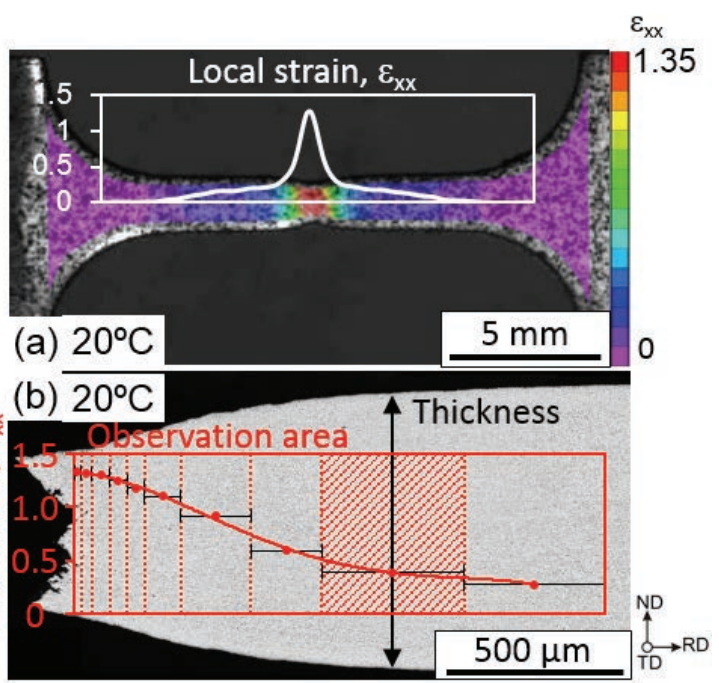

Fig. 3. (a) DIC strain map just before fracture on the specimen deformed at $20^{\circ} \mathrm{C}$ and the local strain along the tensile axis. (b) Observation area for damage evolution curve and corresponding local strains on the specimen. (Online version in color.) 
tured specimens. In order to observe the central region of a specimen, half of the specimen width was removed using mechanical grinding. An example of the damage observation at $20^{\circ} \mathrm{C}$ is shown in Fig. 3(b). The final observation surfaces were prepared using mechanical polishing with colloidal silica. Optical microscopic observations at a high magnification were operated using a fully automated adjustment system of focus, stage shift, and assembling images (Keyence VHX-5000). Since damage incidents appear black on the optical micrograph, they were detected by semi-automated image analysis. The results of the imagebased damage analysis were quantified as damage area fraction, damage number density, and average damage size. The damage indexes for each location were plotted against the local strain in the fractured specimen. The local strain at $20^{\circ} \mathrm{C}$ was obtained by DIC analysis mentioned in Section 2.2. The local strains at cryogenic temperatures were estimated from the reduction in thickness of the respective specimens. Specifically, the reduction in thickness was converted to strain by using a relationship between these two quantities obtained at $20^{\circ} \mathrm{C}$.

\subsection{SEM-based Microstructure Characterization}

Microstructural observations were conducted using secondary electron imaging, EBSD, and ECCI to investigate the relationship between specific microstructures and damages. The secondary electron images were obtained after etching with $3 \%$ nital on a mechanically polished specimen. The specimens for EBSD and ECCI were prepared using mechanical polishing with colloidal silica. The secondary electron imaging and ECCI were performed at 15 and $20 \mathrm{kV}$, respectively. The EBSD analysis was performed at $15 \mathrm{kV}$, with a beam step size of $50 \mathrm{~nm}$.

\section{Results and Discussion}

\subsection{Behavior of Macroscopic Tensile Deformation}

Figure 4(a) shows the nominal stress-strain curves of the DP steel at $20,-100$, and $-180^{\circ} \mathrm{C}$. The flow stress and tensile strength increased with the decrease in deformation temperature. The temperature dependence is a typical behavior when thermal activation process affects the dislocation motion. The temperature dependence of elongation is not monotonic. The elongation increased with the decrease in temperature to $-100^{\circ} \mathrm{C}$, and decreased with the decrease in temperature to $-180^{\circ} \mathrm{C}$. According to the stress-strain response, all the specimens showed necking and subsequently showed failure. Since the work hardening rate at the stage of late deformation increased with the decrease in temperature as shown in Fig. 4(b), the critical strain for satisfying Considère's criterion ${ }^{1}$ increases, which increases the uniform elongation. Therefore, elongation increased with the decrease in temperature to $-100^{\circ} \mathrm{C}$. In order to understand the degradation of elongation at $-180^{\circ} \mathrm{C}$, the reduction in area [Fig. 4(c)] and the appearance of fractured specimens (Fig. 5) are to be noted. Although the specimen
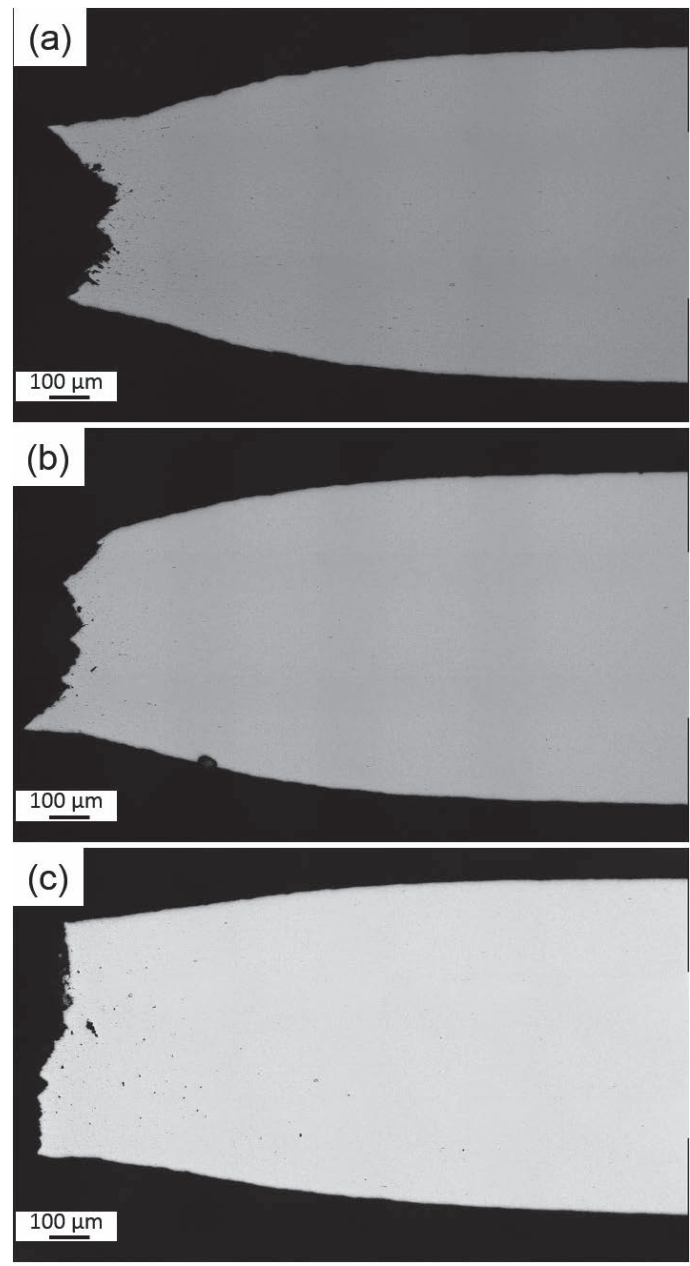

Fig. 5. Appearance of the TD cross-section of the specimens fractured at (a) 20 , (b) -100 , and (c) $-180^{\circ} \mathrm{C}$.
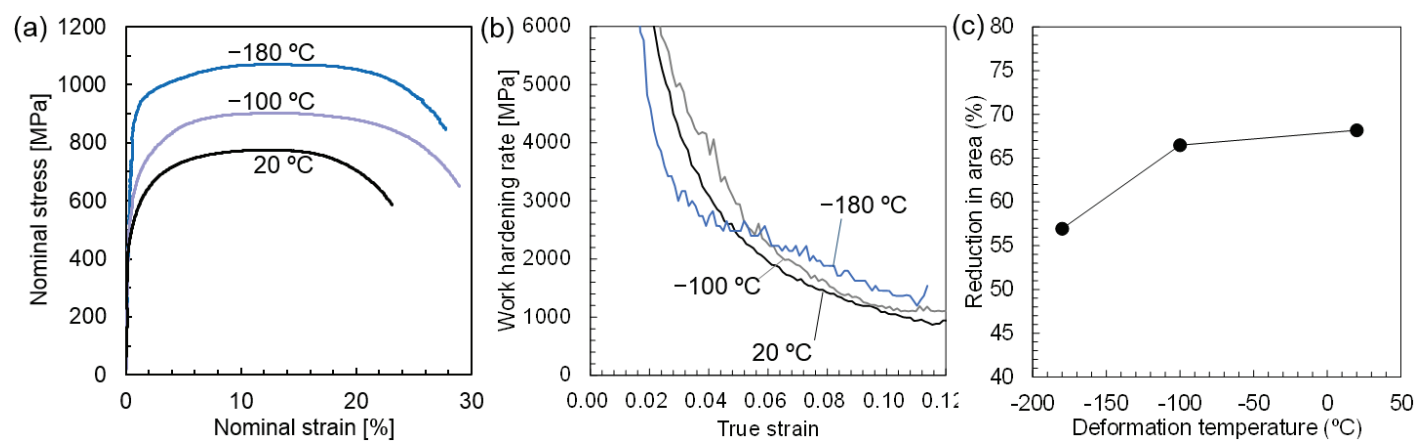

Fig. 4. (a) Nominal stress-strain curves, (b) work hardening curves, and (c) reduction in area at $20,-100$, and $-180^{\circ} \mathrm{C}$. (Online version in color.)

\footnotetext{
${ }^{1} \sigma \geq \mathrm{d} \sigma / \mathrm{d} \varepsilon$ where $\sigma$ and $\varepsilon$ are true stress and true strain, respectively.
} 
fractured at $-100^{\circ} \mathrm{C}$ shows comparable necking to that at $20^{\circ} \mathrm{C}$, the specimen fractured at $-180^{\circ} \mathrm{C}$ exhibits less necking and a relatively flat fracture surface feature. In other words, the degradation of local elongation causes the decrease in elongation at $-180^{\circ} \mathrm{C}$. Moreover, microstructural damage incidents appearing as black dots are visible in the vicinity of the fracture surface, irrespective of the deformation temperature in Fig. 5. These facts indicate that damage arrest and subsequent growth after necking dominate the temperature dependence of local elongation. Therefore, quantitative screening of damage evolution behavior at the three deformation temperatures is necessary.

\subsection{Optical-microscopy-based Analysis in Each Dam- age Evolution Stage}

The damage evolution behaviors at each temperature were investigated quantitatively using the optical-microscopy-based technique. Figure 6 shows the evolution of damage area fraction, damage number density, and average damage size as a function of local strain. According to a previous study, ${ }^{12)}$ damage evolution behavior can be classified into three stages: damage nucleation, damage arrest, and damage growth to fracture. Furthermore, in this study, we discuss the availability and interpretation of the damage evolution curves obtained through optical-microscopy-based analysis with different deformation temperatures.

\subsubsection{Damage Nucleation}

Although SEM-based analysis provided a clear critical strain for damage nucleation in a DP steel in a previous study, ${ }^{12,17)}$ optical-microscopy-based damage quantifications could not determine the critical local strain for two reasons. The first problem is spatial resolution. The minimum detectable area of the digital optical microscope used is $0.1 \mu \mathrm{m}^{2}$, which is insufficient for the detection of small damages in this steel. The other problem is a difficulty in the distinction between damages and etch pits in the optical images. Thus, it is difficult to determine the critical strain for damage nucleation using optical-microscopy-based observations. However, if damage nucleation does not directly affect the fracture, optical-microscopy-based analysis is effective for the characterization of damage evolution behavior. Specifi- cally, the damage can be detected after slight growth and subsequent arrest at the grain boundary or other microstructure arrest sites, enabling reliable quantification of the damage growth behavior. If damage nucleation dominates the fracture behavior, the unknown information of the small defect can be compensated through SEM observations only at a specific region where damage nucleated with the smallest strain. The SEM observation results will be presented in the following sections.

\subsubsection{Damage Arrest}

The present damage quantification successfully shows the damage growth behavior in a DP steel. The variations of the damage number density and average damage size in the damage evolution curves indicate the frequency of the damage nucleation and growth of the damage size, respectively. The damage area fraction, which is the product of damage number density and average damage size, shows the inclusive risk of number density and size. A significant increase of each damage parameter at all the temperatures was not observed at the beginning of deformation, which indicates that damages did not grow before the onset of necking (uniform elongation at $20^{\circ} \mathrm{C}$ is $13 \%$ ). The developments of damage area fraction and number density at 20 and $-100^{\circ} \mathrm{C}$ accelerated after the local strain of 1.0 as shown in Figs. 6(a) and 6(b). The increase in the damage number density shows that the damage nucleation occurred successively until immediately before the fracture. Simultaneously, the average damage size increased only slightly in the damage nucleation regime as shown in Fig. 6(c), which indicates that damage nucleation and arrest occurred repeatedly. Accordingly, the average damage size did not change until the local strain of 1.0. Therefore, the maximum strain for crack arrest in this analysis at 20 and $-100^{\circ} \mathrm{C}$ was approximately 1.0. Similar damage arrest behavior was also observed in the specimen deformed at $-180^{\circ} \mathrm{C}$, and its average damage size was approximately the same as those at 20 and $-100^{\circ} \mathrm{C}$ (approximately $2 \mu \mathrm{m}^{2}$ ). The average damage size that is independent from temperature has a correlation with the martensite grain size which is mostly $1-2 \mu \mathrm{m}$ along the transverse direction. However, at $-180^{\circ} \mathrm{C}$, the fracture strain and critical strain for the onset of increase in the
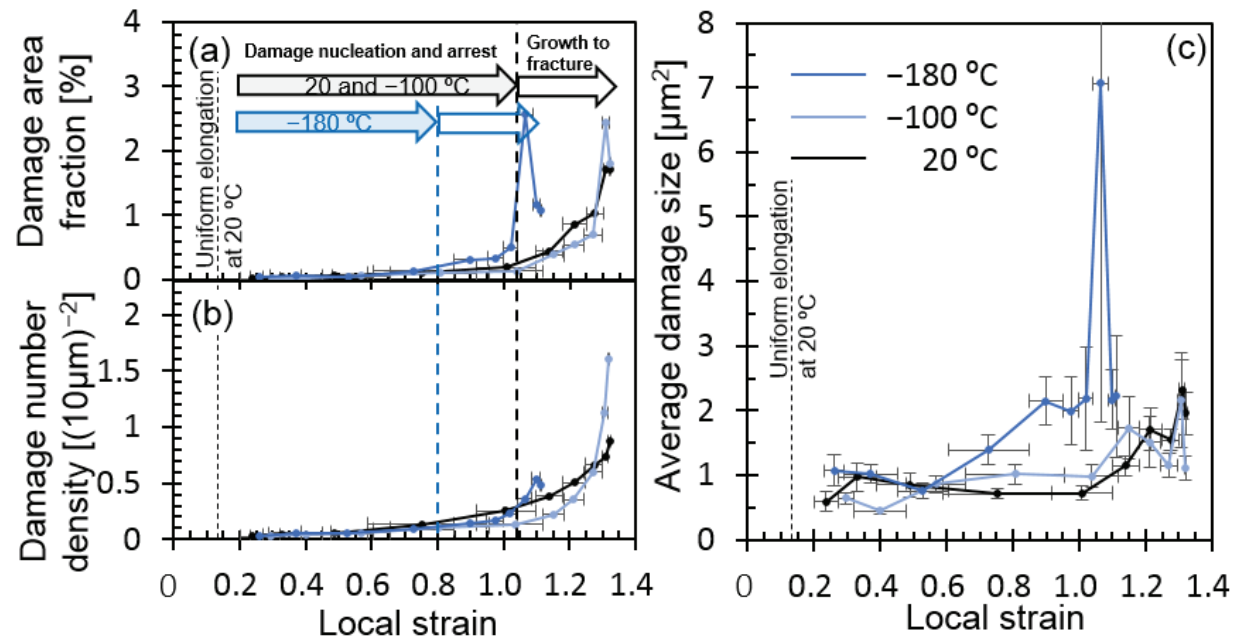

Fig. 6. Damage evolution curves at various deformation temperatures plotted against local strain: (a) damage area fraction, (b) damage number density, (c) average damage size. (Online version in color.) 
damage area fraction are smaller than those at the other temperature conditions. Therefore, we propose two parameters for understanding the relationship between elongation and damage evolution: critical damage size and critical strain for crack growth to fracture. According to the abovementioned result, the critical damage size did not suffer from the effect of decreasing the temperature to $-180^{\circ} \mathrm{C}$, but the critical strain decreased.

\subsubsection{Damage Growth to Fracture}

As mentioned previously, the damage area fraction and average damage size increase sharply after the crack arrest regime. In this regard, the damage quantification revealed that decreasing the temperature to $-180^{\circ} \mathrm{C}$ reduces the critical strain for a rapid increase in the damage area fraction and critical strain for the crack growth to fracture, compared to those at 20 and $-100^{\circ} \mathrm{C}$ as shown in Fig. 6(a). The difference in the critical strains is associated with the occurrence of a change in the fracture mode. Specifically, assuming that the damage growth occurs via ductile mechanism, damage linkage causes the final failure at a critical strain in ferrite. If brittle cracking acts as a triggering factor, the critical stress intensity factor for cleavage fracture at ferrite dominates the final failure. The difference in triggering factor causes significant reduction in the critical strain for the onset of rapid growth of damage area fraction at $-180^{\circ} \mathrm{C}$. Fractographs will be presented in the following section to support this discussion.

\subsection{Support Data: Micro-damage Characterization and Fractrographic Analysis}

Similar to previous studies, ${ }^{12,18)}$ high-resolution SEM observations were performed to investigate the damage evolution mechanisms. High-resolution SEM observations are required owing to the two problems in the optical microscopy-based method. First, the damage nucleation behavior cannot be analyzed as mentioned in Section 3.2.1. Second, the average damage size in damage evolution curves shows the damage size, but the stress around the damage is dependent on the damage shape.

In order to compensate for the lack of crack nucleation information, damage incidents at a small strain are observed using SEM as illustrated in Fig. 7. The damages appear black, whereas the martensite and ferrite appear as bright and dark contrast, respectively. The damages were observed mostly between martensite grains, irrespective of the temperature, probably owing to the martensite-morphology-dependent micro-stress concentration. From the viewpoint of martensite morphology, a major portion of martensite exhibits a plate-like shape in the present steel, owing to the effect of manganese segregation during casting, which causes heterogeneous distribution of austenite stability. Such martensite morphology induces martensite cracking, irrespective of the deformation temperature.

From the viewpoint of crack arrest, as shown in Figs. 8(a) and 8(c), the damages are elongated along the tensile direction in the further deformed region at each deformation temperature. In other words, the crack tip is blunted by the ferrite plastic deformation and the damage stops growing along the thickness direction of the specimen. Damages

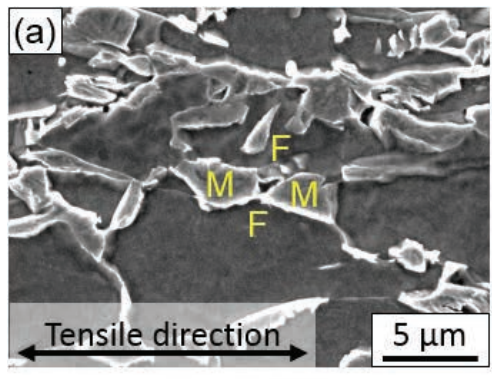

$\varepsilon_{\text {Local }}=0.50$

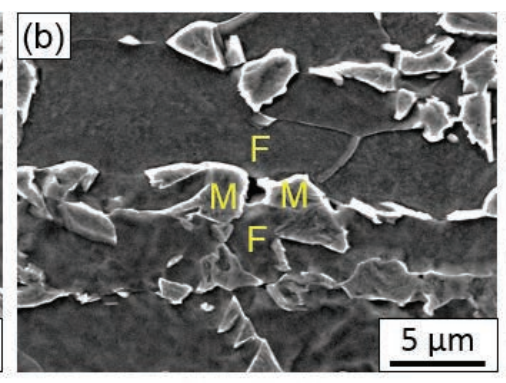

$\varepsilon_{\text {Local }}=0.56$

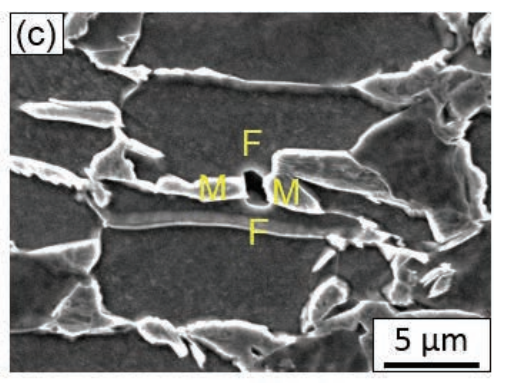

$\varepsilon_{\text {Local }}=0.35$

Fig. 7. Secondary electron images showing damage nucleation at (a) $20^{\circ} \mathrm{C}$, (b) $-100^{\circ} \mathrm{C}$, and (c) $-180^{\circ} \mathrm{C}$. The horizontal direction corresponds to the tensile axis. F: ferrite, M: martensite. (Online version in color.)

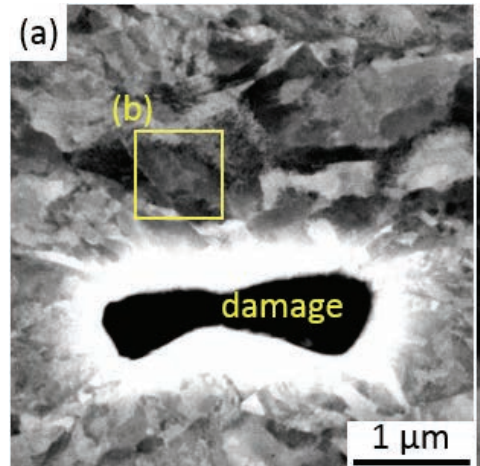

$\varepsilon_{\text {Local }}=1.08$
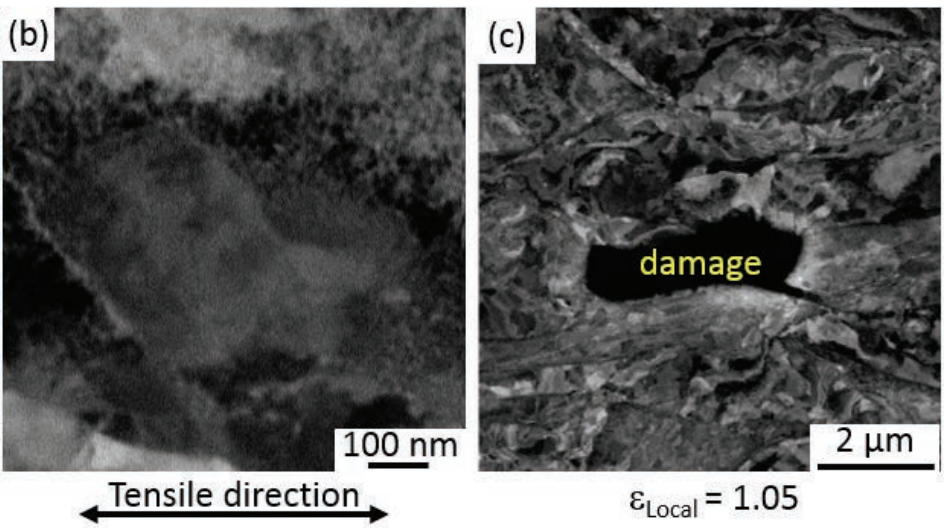

Fig. 8. ECC images showing damage growth in the specimen deformed at (a, b) $20^{\circ} \mathrm{C}$ and (c) $-100^{\circ} \mathrm{C}$. (Online version in color.) 
at ferrite/martensite interface that is a minor initiation site are also arrested when growing to ferrite. The constancy of average damage size indicates that the plasticity of ferrite works as a function of damage arrest capability. The deformed ferrite shown in Fig. 7(b) shows the evolution of dislocation cell structure, which demonstrates that the ferrite is highly deformed. In other words, the plastic deformability of ferrite dominates the crack arrest property. The damage arrest occurs at each deformation temperature as long as the plasticity of ferrite is sufficient even when the flow stress increases with the decrease in the deformation temperature. The stress around the crack tip increases with further deformation owing to work hardening. The work hardening decreases the plasticity of ferrite, and hinders the crack blunting. In the specimen fractured at $-180^{\circ} \mathrm{C}$, some sharp cracks developing perpendicular to the tensile axis were observed, as shown in Figs. 9(a) and 9(b). Specifically, when the local stress at the crack tip reaches the cleavage stress of ferrite, a newly nucleated crack starts to propagate into the ferrite grain by cleavage fracture instead of damage arrest (shown in Figs. 9(c) and 9(d)). The EBSD analysis revealed that the sharp crack propagated along the $\{100\}$ plane of a ferrite grain, which is a typical cleavage plane of body-centered cubic (BCC) crystals. ${ }^{19)}$ The cleavage damage propagation maintains the sharpness of the crack tip; therefore, it is difficult for the damage arrest to occur by a relaxation of stress concentration. Hence, the factors affecting the crack arrest property at cryogenic temperatures are the sharpness of damage tip after martensite cracking, amount of pre-deformation in ferrite before damage nucleation, and flow stress required as the driving force for cleavage crack growth in ferrite. In addition, work hardening at a damage tip also contributes to brittle cracking, because the work hardening deteriorates stress accommodation capability. In other words, damage tip deformation plays ambivalent roles on damage arrest, namely, the crack opening and the work hardening at its tip reduce stress concentration and stress accommodation capability, respectively. Therefore, the damage growth is arrested slightly at ferrite even at $-180^{\circ} \mathrm{C}$, but it instantly restarts to propagate via brittle cracking. Consequently, although a major part of ferrite has sufficient plastic deformability at 20 and $-100^{\circ} \mathrm{C}$, the elongation drastically decreased by decreasing the temperature to $-180^{\circ} \mathrm{C}$, owing to an increase in strength.

Fracture surface morphology was observed to support the discussion on the micro-mechanisms of damage evolution. Figure 10 shows the detailed fracture morphology at the center of fractured surfaces on each specimen. Specimens fractured at 20 and $-100^{\circ} \mathrm{C}$ exhibited a cup and cone type fracture, which is a typical ductile fracture mode, although cleavage feature was observed partially at $-100^{\circ} \mathrm{C}$. In contrast, the fracture surface feature at $-180^{\circ} \mathrm{C}$ was fully cleaved, which validates the discussion on the relationship between the crack arrest property associated with brittle cracking and the drastic reduction in elongation at $-180^{\circ} \mathrm{C}$, mentioned in Section 3.2.3. In addition, the appearance of

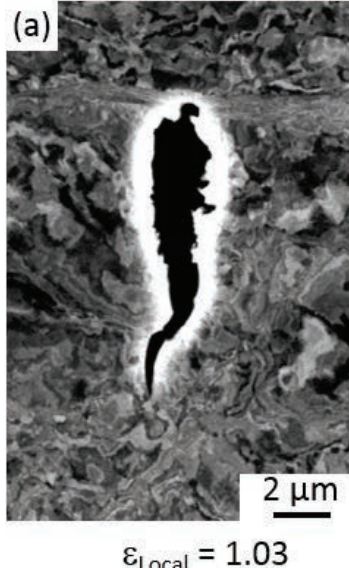

$\varepsilon_{\text {Local }}=1.03$

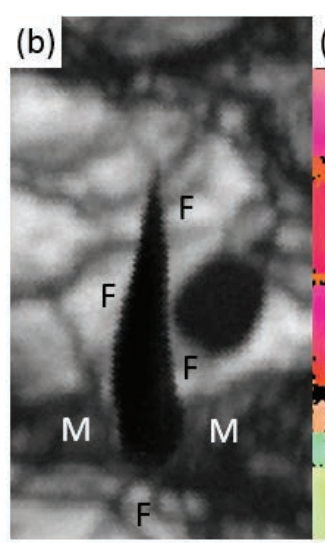

$\varepsilon_{\text {Local }}=1.08$
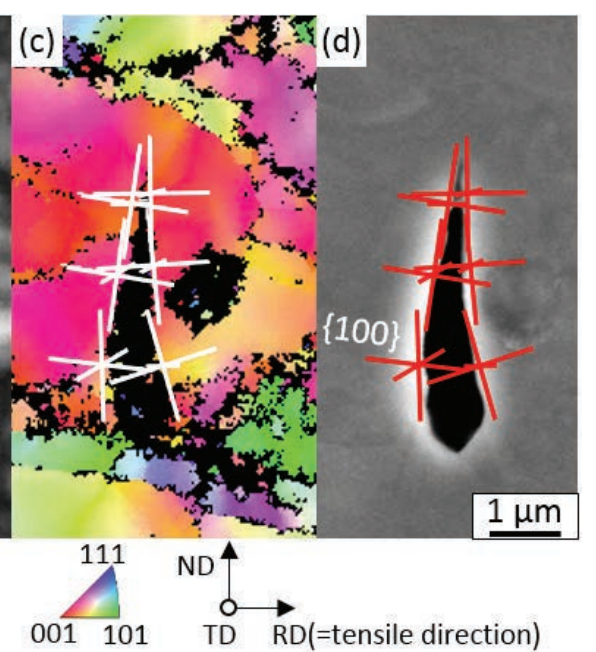

Fig. 9. Damage growth at $-180^{\circ} \mathrm{C}$. (a) ECC image of damage growing perpendicular to tensile direction. (b) IQ and (c) RD-IPF maps showing damage propagation into ferrite grain. (d) Secondary electron image of (b) and (c). White lines in (c) and red lines in (d) show the trace lines of $\{100\}$. (Online version in color.)
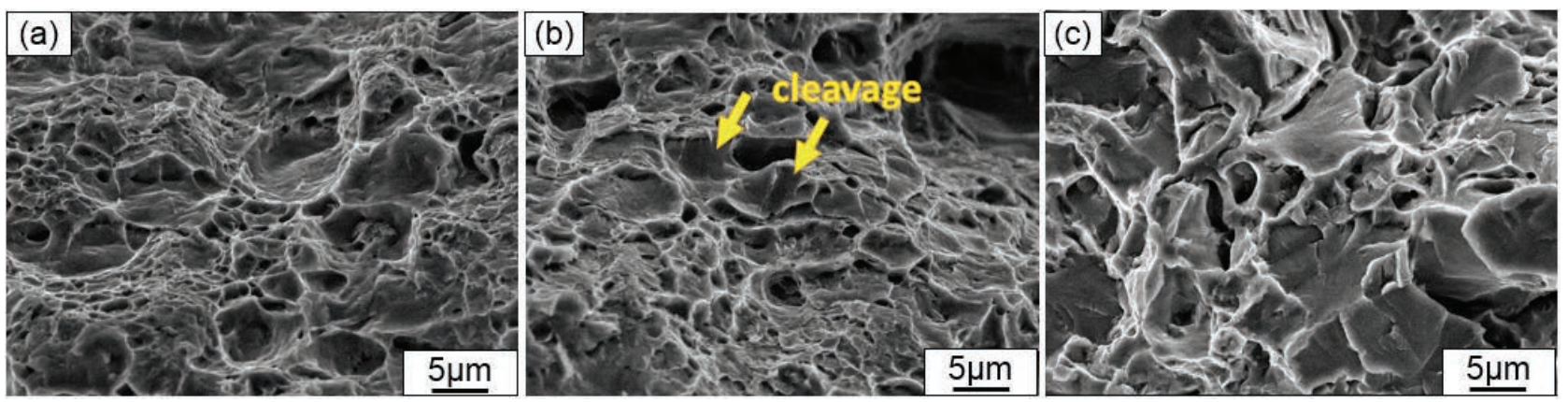

Fig. 10. Fractographs of the specimens deformed at (a) 20 , (b) -100 , and (c) $-180^{\circ} \mathrm{C}$. (Online version in color.) 
the fully cleavage feature indicates that other brittle cracking modes such as intergranular cracking are not the predominant factor on the present cryogenic failure.

\section{Conclusions}

We developed optical-microscopy-based damage quantification method toward screening the damage evolution behavior at various chemical compositions and deformation conditions in practical multi-phase steels such as a DP steel. In this study, optical-microscopy-based quantitative damage analysis was applied for the damage evolution associated with cryogenic tensile deformation of a ferrite/ martensite DP steel. The optical-microscopy-based method does not enable determining the critical strain for damage nucleation owing to the limitation of spatial resolution. This aspect requires high-resolution microscopic characterization using SEM. Other behaviors such as damage nucleation frequency, damage arrest, and damage growth to fracture could be discussed with the optical images. Consequently, the damage evolution behavior in cryogenic temperatures was characterized as follows.

(1) A combined analysis of damage area fraction and damage number density revealed that damage nucleation occurred repeatedly, and these damage incidents were arrested. High-resolution observations indicated that the damage nucleation and damage arrest sites are martensite and ferrite, respectively, irrespective of the deformation temperature.

(2) The damage evolution behavior is classified into regimes of damage nucleation, damage arrest, and damage growth to fracture, irrespective of the deformation temperature in cryogenic temperature range. This indicates that ferrite acts as a damage arrest site even at $-180^{\circ} \mathrm{C}$.

(3) The critical strain for the onset of damage growth to fracture was drastically reduced by decreasing the temperature to $-180^{\circ} \mathrm{C}$. With the support of fractography, the distinct reduction in the critical strain is attributed to the transition of cracking mode from ductile to brittle cleavage mechanisms.

(4) These observations indicate that the fracture in DP steels is controlled by the critical strain for damage linkage in ferrite at 20 and $-100^{\circ} \mathrm{C}$ or at the local critical stress for the cleavage fracture of ferrite at the crack tip at $-180^{\circ} \mathrm{C}$.

\section{Acknowledgements}

M. Koyama acknowledges the financial support of JSPS KAKENHI (JP16H06365; JP17H04956).

\section{REFERENCES}

1) T. Senuma: ISIJ Int., 41 (2001), 520

2) C. C. Tasan, M. Diehl, D. Yan, M. Bechtold, F. Roters, L. Schemmann, C. Zheng, N. Peranio, D. Ponge and M. Koyama: Ann Rev. Mater. Res., 45 (2015), 391.

3) T. Hüper, S. Endo, N. Ishikawa and K. Osawa: ISIJ Int., 39 (1999), 288.

4) J. Marteau, H. Haddadi and S. Bouvier: Exp. Mech., 53 (2013), 427.

5) E. Ahmad, T. Manzoor, K. L. Ali and J. I. Akhter: J. Mater. Eng. Perform., 9 (2000), 306.

6) K. Hasegawa, K. Kawamura, T. Urabe and Y. Hosoya: ISIJ Int., 44 (2004), 603.

7) J. Lemaitre, R. Desmorat and M. Sauzay: Eur. J. Mech. A-Solid., 19
(2000), 187

8) C. C. Tasan, J. P. M. Hoefnagels and M. G. D. Geers: Acta Mater., 60 (2012), 3581

9) C. L. Chow and J. Wang: Int. J. Fract., 33 (1987), 3.

10) C. L. Chow and J. Wang: Eng. Fract. Mech., 27 (1987), 547.

11) M. Kahziz, T. F. Morgeneyer, M. Mazière, L. Helfen, O. Bouaziz and E. Maire: Exp. Mech., 56 (2016), 177.

12) M. Koyama, C. C. Tasan, E. Akiyama, K. Tsuzaki and D. Raabe: Acta Mater., 70 (2014), 174.

13) G. Avramovic-Cingara, C. A. R. Saleh, M. K. Jain and D. S. Wilkinson: Metall. Mater. Trans. A, 40 (2009), 3117.

14) K. Park, M. Nishiyama, N. Nakada, T. Tsuchiyama and S. Takaki: Mater. Sci. Eng. A, 604 (2014), 135.

15) S. Takagi, Y. Tokita, K. Sato, T. Shimizu, K. Hashiguchi, K. Ogawa, K. Mimura and S. Tanimura: SAE Trans. J. Mater. Manuf., 114 (2015), 166.

16) S. Takagi, K. Miura, O. Furukimi, T. Obara, T. Kato and S. Tanimura: Tetsu-to-Hagané, 83 (1997), 748.

17) M. Koyama, C. C. Tasan, T. Nagashima, E. Akiyama, D. Raabe and K. Tsuzaki: Philos. Mag. Lett., 96 (2016), 9.

18) T. Kaneko, M. Koyama, T. Fujisawa and K. Tsuzaki: ISIJ Int., 56 (2016), 2037.

19) R. Abbaschian and R. E. Reed-Hill: Physical Metallurgy Principles, Cengage Learning, Stamfrord, CT, (2008).

20) R. L. Fleischer: J. Appl. Phys., 33 (1962), 3504.

\section{Appendix}

The plastic deformation of metals arises from the dislocation movement, and the strain rate $\dot{\gamma}$ can be written in two ways: ${ }^{20)}$

$$
\begin{array}{r}
\dot{\gamma}=N v b, \ldots \ldots \ldots \ldots \ldots \\
\dot{\gamma}=N f b L \exp (-U / k T),
\end{array}
$$

where $N$ is the number of dislocations, $v$ is the average velocity of a dislocation, $b$ is the slip vector of the dislocation, $f$ is the frequency of vibration of a dislocation segment of length $L, U$ is the activation energy to move the dislocation, $k$ is the Boltzmann's constant, and $T$ is the temperature. The activation energy $U$ is expressed as

$$
\begin{aligned}
& U=F_{0} b\left[1-\left(\tau / \tau_{0}\right)^{p}\right]^{q} \\
& (0 \leq p \leq 1,1 \leq q \leq 2),
\end{aligned}
$$

where $F_{0}$ is the force on a dislocation at $0 \mathrm{~K}, \tau$ is the critical resolved shear stress, and $\tau_{0}=\left(F_{0} / b L\right)$ is the critical resolved shear stress at $0 \mathrm{~K}$. Substituting Eq. (3) into Eq. (2), the strain rate $\dot{\gamma}$ can be written as

$$
\dot{\gamma}=N f b \operatorname{Lexp}\left(-F_{0} b\left[1-\left(\tau / \tau_{0}\right)^{p}\right]^{q} / k T\right),
$$

Further, BCC metals have sufficient slip system. Thus, the flow stress of polycrystalline BCC metals $(\sigma)$ is

$$
\tau=\sigma / 2 \text {. }
$$

By substituting Eq. (5) into Eq. (4), $\sigma$ is described as a function of temperature and strain rate:

$$
\begin{aligned}
& \frac{\sigma}{2 \tau_{0}}=\left\{1-\left(A T \log \frac{B}{\dot{\gamma}}\right)^{\frac{1}{q}}\right\}^{\frac{1}{p}} \\
& \text { where } A=\frac{k}{F_{0} b}, B=N f b L .
\end{aligned}
$$

Therefore, the temperature effect on flow stress can be converted to the strain rate effect using these equations. 